\title{
MODELO TERRITORIAL INNOVADOR Y ARTICULACIÓN URBANA EN EL PONIENTE ALMERIENSE
}

\author{
Luis Miguel Sánchez Escolano \\ Dpto. de Análisis Geográfico Regional y Geografía Física \\ Universidad de Granada
}

\section{RESUMEN}

El Poniente Almeriense es hoy un espacio altamente productivo que cuenta con una economía diversificada sostenida en la agricultura intensiva de alta tecnificación, la industria agroalimentaria, los servicios a empresas y el turismo de sol y playa. Así mismo, se ha consolidado como un territorio competitivo y con capacidad de adaptación a la realidad económica globalizada, propicio a la innovación empresarial y territorial. Pero el desarrollo y consagración de este modelo económico ha acarreado profundas transformaciones urbanas y territoriales que han reconfigurado por completo esta comarca, y todo ello en un marco de insostenibilidad ecológica marcado por la depredación de recursos muy escasos. El presente trabajo aborda, a partir del análisis de la dinámica territorial que configuró este espacio desde mediados del siglo XX, los principales efectos de estas transformaciones, focalizando nuestra atención en la dinámica urbana y los procesos de innovación territorial acaecidos en estos años.

Palabras clave: ordenación territorial, sistema urbano, generación de modelos innovadores, poniente almeriense.

\section{ABSTRACT}

\section{Innovating territorial model and urban articulation in Western Almería}

Western Almeria today is a highly productive space that has a diversified economy sustained in the intensive agriculture mechanization, agribusiness, business services and sun and beach tourism. In addition, the setting has become a competitive region which is able to adapt to global economic realities, suitable for business and territorial innovation. But the development and establishment of this economic model has brought profound urban and territorial changes that have completely reconfigured this region, all within a framework of ecological unsustainability marked by scarce resources. This paper addresses, based on the analysis of territorial dynamics that have shaped this area since the mid-twentieth century, the main effects of these changes, focusing our attention on urban dynamics and territorial innovation processes occurring during these years.

Keywords: territorial management, urban system, generation of innovative models, Western Almeria.

\section{INTRODUCCIÓN}

En nuestros días, el poniente almeriense es, ante todo, sinónimo de éxito económico y territorial. Su sistema productivo, en constante mejora y fruto de una dinámica innovadora que es inherente a la supervivencia de estructuras territoriales en un mundo globalizado y fuertemente competitivo (Ruíz, 2004; Larrubia, 2010; Jiménez, 2008, 2011; Caravaca et al., 2009; Aznar et al., 2010), ha transmitido a la sociedad la imagen de un espacio lleno de oportunidades para la actividad económica, en constante crecimiento demográfico, con un mercado de trabajo pujante, y que se erige en ejemplo paradigmático -en lo bueno y en lo malo- de lo que es una sociedad multiétnica en España. El camino recorrido hasta

Contacto: $\underline{\text { lmsescolano@ugr.es }}$ 
llegar a este escenario ha sido largo y trabajoso. Desde aquellos campos de artos y esparto en los que pastaba el ganado invernante que huía de los fríos de Sierra Nevada y la alta Andalucía, ejemplo de árido secarral batido contantemente por el implacable viento, y en el que no era posible la agricultura entendida en sus formas y técnicas tradicionales, hasta la realidad actual, en el que algunas de las estructuras y procesos agrarios más modernos del mundo conviven con lujosos resorts turísticos entre nudos de autovía y modernos edificios de diseño, se han sucedido generaciones de obstinados trabajadores que, atraídos por la iniciativa pública y el buen hacer de los técnicos, han conseguido colocar a esta comarca y a la provincia de Almería bajo el foco mediático y científico, siendo constante actualidad por sus innovaciones técnicas, sus logros productivos, y la creación de espacios de oportunidad para empresas y emprendedores.

Junto a lo anterior, el proceso de transformación radical sufrido por este territorio determina toda una serie de consecuencias directas sobre la red urbana comarcal. La estructura preexistente, que contaba con las ciudades medias de Berja y Adra en el occidente y la ciudad de Almería a oriente como únicas referencias de entidad, dejaba un gran espacio libre en el centro de la comarca, insuficientemente articulado en torno a los pequeños núcleos rurales de montaña de Vícar, Enix y Felix por un lado, y los costeros de Roquetas de Mar o Balerma por otro. La solitaria carretera nacional 340 atravesaba de oeste a este un territorio despoblado en el que el único asentamiento lo constituían los pequeñas caseríos rurales (El Ejido era una de ellos) que salpicaban el llano en aquellos puntos en los que alguna cañada o punto de extracción de agua permitía el asentamiento humano. Las actuaciones del Instituto Nacional de Colonización (INC) a partir de 1941, la llegada de nuevos colonos a las tierras puestas en regadío procedentes del éxodo rural que huía de la pobreza en la vecina Alpujarra, unida a la genialidad local para hacer frente a la indigencia pluviométrica, luchar contra el viento y sacar el máximo provecho de suelos pobres y pedregosos, dio como resultado el desarrollo del cultivo enarenado, que se vio complementado seguidamente con importantes innovaciones en esta materia (introducción del plástico, de nuevas variedades hortofrutícolas, aumento de las extracciones de agua del acuífero, nuevas técnicas de cultivo y riego) y con el inicio de la actividad turística en torno a centros planificados por el gobierno para esta actividad. En definitiva, se trataba, con ayuda de la técnica y de la planificación, de ordenar y poner en valor un espacio, generando riqueza a partir de los hasta entonces desaprovechados recursos que proporcionaba el medio comarcal (agua en acuíferos, fuerte insolación, problemático régimen de vientos), sacando el máximo partido de la cultura técnica y de aprovechamiento de los recursos propia de las gentes del sureste español.

Estas actuaciones desencadenaron una nueva dinámica territorial, que rápidamente se vio consolidada en los años 70 y 80 del pasado siglo, la cual ha basado una parte fundamental de su éxito económico en la generación de redes y estructuras adaptables a los cambios que pudieran producirse en los distintos mercados en los que competía el poniente almeriense. Ya sea en el mundo agrícola y su pujante industria agroalimentaria anexa, con el imprescindible soporte y conocimiento técnico que año a año es necesario revisar y poner al día, ya sea en el turístico, con un desarrollo complementario de distintas modalidades -sol y playa, golf, cultural, congresos-. El poniente almeriense ha demostrado haber sido capaz de generar una estructura empresarial dinámica y flexible que ha superado con éxito la multitud de retos que, a lo largo de estas últimas décadas, se le han ido presentando de forma reiterada y cada vez con más premura y en forma de un desafío mayor. La falta de agua que sostiene la agricultura, la ausencia de espacio para expandir el área invernada, el aumento del coste de producción de cada cosecha (semillas, químicos, tratamientos higiénicos), la feroz competencia entre actividades por los recursos (agua y suelo principalmente, pero también paisaje e infraestructuras), el aumento de la competencia exterior, o la necesidad de una mayor cooperación y concentración de los productores y agentes económicos para sobrevivir con éxito en un mundo globalizado y controlado por grandes multinacionales, se han ido sucediendo como retos a los que la población local ha ido haciendo frente a partir de una capacidad de adaptación y renovación admirable, un tejido empresarial adaptado a los vaivenes del mercado, y una industriosidad que brilla por su ausencia en otros espacios rurales andaluces.

En el presente trabajo queremos combinar estas dos perspectivas. Por un lado, la del análisis y diagnóstico geográfico de un espacio altamente transformado y muy pujante dentro del territorio andaluz, atendiendo especialmente al protagonismo que en estas transformaciones ha tenido su sistema 
urbano, estructura rectora del crecimiento y la articulación espacial. Por otro, se trata de identificar las claves que definen a este territorio como un espacio competitivo y con capacidad de innovación, desentrañando las dinámicas y factores explicativos que nos acerquen a comprender las bases sobre las que se sustenta su exitoso modelo. Con esto pretendemos, por un lado, poner en valor la función rectora llevada a cabo por los núcleos del sistema urbano comarcal -constituido actualmente por una mayoría de ciudades medias-, en los procesos de desarrollo territorial que han tenido lugar en esta comarca en los últimos años. En segundo lugar, nos permitirá valorar el papel de estos centros como elementos clave en la ordenación interna y la articulación externa de este espacio. De forma complementaria, este tipo de estudio nos dará las claves para saber más sobre las nuevas dialécticas espaciales generadas por el profundo cambio -tecnológico, productivo y social- habido en las últimas décadas, y de las que el sistema urbano del poniente almeriense es su más fiel reflejo. Así mismo, con sus contradicciones y problemáticas asociadas -ecológicas y sociales principalmente-, abordaremos cómo las gentes del poniente almeriense han conseguido generar un territorio caracterizado, sobre todas las cosas, por su capacidad competitiva y de adaptación, predispuesto a la innovación empresarial, tecnológica y, en definitiva, territorial.

\section{CONFIGURACIÓN TERRITORIAL DEL PONIENTE ALMERIENSE}

\subsection{El litoral andaluz y su dinámica territorial}

El litoral andaluz constituye, en la actualidad, junto con las grandes áreas metropolitanas, la base territorial y de articulación de Andalucía. Una región tan grande como la andaluza, encuentra muchos problemas para articular un sistema territorial definido, y desde finales del siglo XX, el litoral, con la llegada de las grandes infraestructuras, la consolidación del modelo de ocupación -basado en la agricultura intensiva y el turismo- y el fuerte dinamismo demográfico y económico en esta zona, consiguió erigirse junto con el valle del Guadalquivir en la base del sistema de asentamientos y del poblamiento regional.

El desarrollo del litoral andaluz se ha consolidado, por tanto, como el nuevo foco principal en la atracción de actividades y personas, alterador del equilibrio social, urbano y económico preexistente, y debido a esto, en espacio generador de nuevos conflictos. Y todo esto se deriva de la apuesta realizada en este ámbito por la intensificación de usos y una fuerte especialización productiva, con efectos drásticos sobre el paisaje y los recursos naturales locales.

Debido a ello, el litoral se ha convertido en nuestros días en el motor económico de Andalucía, en el espacio más dinámico tras las grandes aglomeraciones urbanas de la región, por lo que la ordenación del territorio muestra una especial atención hacia los procesos que tienen lugar en el mismo y el enorme potencial de futuro que ofrece. Se erige, por tanto, en un referente ineludible en la construcción de procesos y modelos territoriales en Andalucía (De la Hera, 1998: 118). En este sentido, la política territorial juega un papel primordial en la definición global de los límites ecológicos y territoriales de las actividades que hoy sustentan la economía del litoral andaluz, y la tabla de salvación que aporta un modelo integrador de respeto a los recursos locales en el marco de una apuesta decidida por el desarrollo territorial integrado.

En este contexto, el poniente almeriense constituye ejemplo paradigmático tanto en lo que respecta a las transformaciones comentadas, como a la velocidad y ferocidad con que esas transformaciones han acarreado consecuencias de tipo estructural sobre el territorio, el sistema urbano y la dinámica demográfica y social de esta parte del litoral mediterráneo andaluz.

\subsection{El modelo agrícola del poniente de Almería}

La historia del sector agrícola del poniente almeriense tal y cómo hoy lo conocemos arranca mucho antes de la llegada de las infraestructuras y del desarrollo de la planificación regional y subregional.

Entre los grandes hitos de esa historia, que tiene su partida en los esfuerzos públicos para promover el regadío y la agricultura en las zonas más pobres de una España de por sí pobre, encontramos la aprobación de la Ley de Colonización de Grandes Zonas (1939), donde se definió el proyecto para la colonización 
del campo de Dalías, ámbito declarado de interés nacional en 1941. Más adelante llegó la Ley sobre Colonización y Distribución de la Propiedad en Zonas Regables (1949), con la que comienzan, en sectores que reunían características especiales, las actuaciones del Instituto Nacional de Colonización (INC), mediante declaración de Zonas de Interés Nacional, que permitieron la creación y puesta en marcha de las infraestructuras necesarias para la extracción de agua subterránea mediante pozos, la irrigación de los campos -que previamente habían sido ordenados y repartidos entre colonos-, creando así mismo asentamientos de nueva planta que ordenaran el sistema territorial y urbano de un espacio que entraba en una fase de radical transformación (destacamos los casos de San Agustín, Las Norias o La Mojonera). En 1953 se formaliza el primer Plan General de Colonización (1953), que tuvo su continuidad en seis planes más hasta 1977.

Muy destacable fue, en este sentido, la labor del INC en lo referido a la ocupación de las nuevas tierras agrícolas que se desarrollaban sobre el antiguo erial. No sólo se generaba un marco productivo basado en el nuevo regadío, sino que, en lo relacionado con la propiedad de la tierra, se distribuyó de tal forma que se acabó por generar una clase de medianos propietarios con pequeña extensiones de tierra que, si bien eran pequeñas y, en otras zonas de España, habían demostrado ser insuficientes para mantener a una familia, eran extraordinariamente productivas y encontraron rápidamente acomodo en las redes comerciales nacionales. Este proceso inicial, estrictamente agrario y social, desencadenó toda una serie de fenómenos de carácter económico, social y territorial, que comenzaron con el aumentando del nivel de vida de la población, y continuaron con la llegada masiva de inmigrantes procedentes del hinterland rural y decadente del campo de Dalías. En este marco, el progreso técnico y las mejoras constantes comenzaban a aparecer como resultado, por un lado, del dinamismo social y los esfuerzos del cuerpo técnico del INC, y por otro, debido a la toma de conciencia, por parte de la población y de las autoridades, de las enormes potencialidades que encerraba la zona para el desarrollo de agricultura extratemprana. Los primeros grandes hitos de esta historia de mejoras demuestran una mezcla sobresaliente entre, por un lado, los elementos básicos de la técnica y cultura agrícola tradicional aplicados a los nuevos aprovechamientos de la zona (uso de la ceniza, la capa de estiércol, los setos vivos corta vientos), y por otro, la inclusión de los mejores resultados de la investigación oficial que respaldaba el proceso de ocupación del espacio y apostaba decididamente por el éxito de este modelo productivo. En 1956, se implementa el enarenado como técnica de cultivo. En 1961 se construye el primer invernadero por parte del IRYDA en una finca de pruebas. A partir de de 1968, se generaliza el cultivo "tipo parral" cubierto con plásticos, en lo que constituye todo un símbolo de la simbiosis que empezaba a producirse entre tradición y modernidad.

El éxito del modelo derivó en un aumento exponencial en la extensión invernada en la comarca, pasando de 3.081 has en 1976, a 9.657 has en 1984 (Hernández Porcel, 1994: 157), y de ahí hasta las 18.694 has de 1999, con una cierta estabilización en los siguientes años (Jiménez, 2011), debido a la saturación del espacio agrícola llano comarcal. Esta expansión continuada acabó por configurar la que es una de las pocas obras humanas visible desde el espacio, una de las grandes -y más llamativastransformaciones humanas de la faz de la tierra en el siglo XX.

Pese a todo, hubo un momento de cierto estancamiento a mediados de los años 80. Esto se debió a la materialización de una incertidumbre de la que se tenía constancia desde el mismo comienzo en el desarrollo agrícola y que, en aquellas fechas, ya era también turístico. En 1984, la administración pública prohibió el incremento de la superficie regada en el campo de Dalías debido a los numerosos casos de sobreexplotación de acuíferos que se estaban produciendo y los primeros problemas por salinización. Pese a todo, una flexibilización posterior de esta prohibición, unida a la falta de conciencia ambiental existente en la sociedad, y los altos rendimientos económicos que seguían generando los invernaderos, no sólo no se frenó la expansión agrícola ni turística, sino que ha seguido incrementándose año a año junto con el consumo de aguas subterráneas en la comarca.

Muy importante, a la hora de reforzar las tendencias territoriales desatadas con el cambio agrícola y la aparición del turismo de masas, fueron los cambios en infraestructuras. Todo esto supuso el cambio en la conectividad interna y externa y el aumento exponencial en las posibilidades de desarrollo y crecimiento 
de la economía comarcal. Hasta los años 90 del pasado siglo, la comarca se había convertido en un punto saturado y problemático en el recorrido de la N-340, con exceso de circulación ya a mediados de los 80 (Ocaña et al., 1992: 143). Esto se solucionó parcialmente con la creación de la A-7, la autovía del Mediterráneo, a partir de 1990, terminada pocos años después, y fue la clave para la salida de productos locales hacia Europa por el Mediterráneo. Siempre en camión y en ausencia de trenes de mercancías, característica deficiencia, ya histórica, en el sureste español. Si bien esto mejoró notablemente la conectividad comarcal con muchos de los destinos receptores de la producción. Así mismo, podemos marcar un momento, un hito que define un antes y un después, en la historia comercial de la comarca: la entrada de España en la CEE, facilitó enormemente el acceso de los productos almerienses a los mercados europeos, con alto poder adquisitivo, y así mismo, abrió las puertas a la llegada de turistas.

En los años 1990 ya se hablaba de una agricultura semi-industrial, por la alta intensificación a la que se ha había llevado a la producción, y la cantidad de inputs externos que en ella se consumían (Hernández, 1994: 148). Pero lo que realza la singularidad del modelo socioeconómico del poniente almeriense es el hecho de que el sector puntero que se ha desarrollado ha sido una agricultura comercial, intensiva, y de altos rendimientos (Aznar et al., 2010: 160).

Con el desarrollo económico vino el desarrollo territorial, y con él, grandes proyectos imprescindibles para garantizar la pervivencia del modelo en marcha: la ya citada autovía A-7 en primer lugar, y también proyectos de expansión del regadío, ordenación de los usos del suelo, gestión integral de residuos urbanos y agrícolas, que ya fueron implementados en un etapa en la que la planificación y la ordenación del territorio marcaban las directrices a seguir para la consecución de un espacio plenamente organizado internamente y articulado con el resto de Andalucía. En definitiva, cambios y más cambios sobre un territorio cada día más densificado de usos, muchos de ellos agresivos con el medio y, en algunos casos, incompatibles entre sí.

\subsection{El otro pilar del modelo de desarrollo del poniente almeriense: el turismo}

El turismo se ha erigido en la segunda actividad en importancia territorial y económica de la comarca, tras la agroindustria y el invernadero, y se caracteriza por ser más dispersa en su distribución y menos intensiva, si bien el fuerte crecimiento reciente está densificando ciertos espacios estratégicos en su expansión.

El origen del desarrollo turístico en el poniente almeriense tuvo unos inicios marcados por la mano ejecutora de la planificación pública. Concretamente, tras la aprobación de la Ley de Centros y Zonas de Interés Turístico Nacional (1963), que sirvió, por un lado, para planificar desarrollos turísticos a escala nacional. Concretamente en la provincia de Almería, si bien no se produjo para el poniente ninguna catalogación específica de zona de actuación, si tuvo su plasmación en la puesta en marcha de actuaciones aisladas en un territorio hasta entonces centrado en la expansión agrícola y que, pese a sus innumerables potencialidades para el turismo de sol y playa, no había sabido generar oferta estructurada alguna. Pese a ello, el primer Centro de Interés Turístico Nacional (CITN) de Andalucía -y de España- fue aprobado en Aguadulce, anejo de Roquetas de Mar, en octubre de 1964, con una extensión de 75 has que se fueron acrecentando en la renovación de los sucesivos planes parciales municipales de 1967 y 1973. Más tarde, en 1967, se repitió el proceso con un nuevo plan turístico para Roquetas de Mar. El 1976, y tras la consolidación del proyecto anterior, se puso en marcha el CITN "El Oasis de la costa del Sol", que más tarde acabaría llamándose Almerimar, en el extremo sur del actual término municipal de El Ejido.

Los primeros trabajos ya indicaban que el desarrollo turístico en Almería tenía ciertas característica específicas, que en muchos casos, condicionaban su éxito como modelo alternativo de desarrollo para este espacio: extrema dispersión, resultado de iniciativas puntuales y aisladas, con una extrema velocidad en su expansión, lo que hacía que ésta estuviera fuera de control en muchas ocasiones (Lara, 1980). Durante los años 80 este modelo fue consolidándose al amparo de una mejora generalizada de las condiciones de vida en España y Europa, cuya población, con altos niveles de renta, comenzaba a llegar al poniente y podía permitirse el lujo de poseer una segunda vivienda en la playa o en los novedosos complejos 
urbanísticos nacidos junto a los flamantes campos de golf comarcales (hay en la actualidad tres campos, el de Almerimar, el más antiguo, Playa Serena en Roquetas y la Envía Golf en Vícar). El exitoso devenir del turismo en la zona acabó consolidando estos proyectos, si bien con tendencias y comportamientos basados en distintas realidades. Aguadulce acabó por convertirse, debido a su proximidad (apenas $11 \mathrm{kms}$ ), en primera residencia de muchos almerienses que no deseaban vivir en la capital. Roquetas, tanto el núcleo tradicional como la zona turística, acabaron por fundirse en una enorme aglomeración urbana que hoy conforma el núcleo principal del municipio, cuya expansión descontrolada en los últimos años a lo largo de toda la fachada litoral ha llegado a amenazar la conservación del paraje natural Punta Entinas-Sabinar. Almerimar por su parte es hoy el centro del turismo residencial extranjero en la comarca, y no presenta los espectaculares desarrollos comerciales que podemos encontrar en Roquetas o Aguadulce.

Con la aplicación del Plan de Ordenación Subregional del Poniente Almeriense, se consiguió dirigir y aglutinar el crecimiento urbano asociado al turismo, evitando el habitual fenómeno de los desarrollos dispersos en nuevas localizaciones, y consiguiendo que cada ampliación y nueva promoción urbanística, estuviera unida físicamente a los núcleos preexistentes. A esto también colaboró la elevadísima rentabilidad económica y la presencia negativa, desde el punto de vista de los valores paisajísticos preferidos por el turista, de los invernaderos, que consiguen que se produzca una especialización del uso del suelo turístico en aquellos espacios que previamente ya reunían características apropiadas para el mismo, y donde la presencia de los plásticos y sus efectos (olores, residuos) era menos evidente y llamativa. De ahí el peligro, tantas veces denunciado, que sufren los espacios naturales comarcales a manos de la expansión urbanística, ya que constituyen los últimos reductos frente a los perniciosos efectos visuales y ambientales del invernadero (Rodríguez, 1991: 335-338).

Cuadro 1. El sector turístico y residencial en el poniente almeriense, 2010.

\begin{tabular}{|c|c|c|c|}
\hline & Poniente & Total provincial & Relación en \% \\
\hline $\mathrm{N}^{\mathrm{o}}$ hoteles & 34 & 134 & 25,4 \\
\hline $\mathrm{N}^{\circ}$ hostales/pensiones & 24 & 159 & 15,1 \\
\hline $\mathrm{N}^{\circ}$ plazas hoteles & 13.482 & 26.269 & 51,3 \\
\hline $\mathrm{N}^{\circ}$ plazas hostales/pensiones & 727 & 3.914 & 18,6 \\
\hline
\end{tabular}

El poniente almeriense concentra en la actualidad una buena parte del conjunto del sector turístico provincial, y si bien en los años 80 constituía la avanzadilla provincial en este sector (con un peso relativo mayor que el actual), el nacimiento de nuevos focos turísticos ya consolidados en el levante (Cabo de Gata-Nijar, Mojácar-Vera) y en el interior rural (Alpujarra, Los Vélez) ha hecho decrecer la importancia relativa del turismo comarcal en la provincia. En este sentido, destacamos el peso importante que aún mantiene la comarca en materia de capacidad hotelera, ya que concentra más del $25 \%$ de los hoteles y el $51 \%$ del número de las plazas provinciales, debido sin duda a la diversificación del modelo económico impulsada desde el propio sector, que ha intentado diversificar sus posibilidades con la organización de congresos, revalorizando el producto cultural local, y aumentando su oferta en campos de golf.

En definitiva, el poniente de Almería ha afianzado, en éstas últimas décadas, un complejo sistema productivo que se basa en dos pilares fundamentales. Uno principal en el sector agroalimentario y su industria adyacente, icono comarcal y base de su imagen de marca dentro y fuera de Andalucía, y otro, de creación más tardía y con menos peso en la economía, que es el del turismo, plenamente arraigado en sus estructuras y que hace un gran esfuerzo por diversificar su producto y mejorar su oferta.

\subsection{El papel de las herramientas de planificación}

Como en todo proceso de cambio territorial, el papel de la planificación ha sido fundamental. Para ordenar el crecimiento, reconducir dinámicas, y acotar problemáticas y riesgos. La historia de la 
planificación y la ordenación del territorio en Andalucía, es, pese a algunas sombras injustificables, la historia de un éxito. Una necesidad básica por la que clamaba una región sin eficiente articulación interna y en la que muchos de los procesos más agresivos y transformadores del medio físico y humano -como fue la puesta en marcha de los polos de desarrollo industrial, la irrupción del turismo de masas, el desarrollo de la agricultura intensiva en el litoral, o finalmente la aparición y desarrollo explosivo de las áreas metropolitanas en torno a las principales ciudades-, estaban teniendo lugar sin un plan territorial unitario ni un marco ordenativo que integrase esas actividades y procesos en su contexto territorial, que evitara desmanes y atrocidades contra el medio natural, el patrimonio cultural y la estructura territorial preexistente. En el caso del poniente almeriense, y teniendo en cuenta la historia planificadora andaluza, la ordenación hizo su aparición en fechas tempranas. De hecho, su correspondiente plan subregional, habiendo entendido la administración regional que estaba ante un espacio que había sufrido cambios radicales sin control planificador, fue el segundo de Andalucía en redactarse y entrar en vigor (en 2002), tras el del área urbana de Granada y antes que los de espacios emblemáticos de la organización territorial andaluza actual, como la costa del Sol occidental o las aglomeraciones urbanas de Sevilla y Málaga.

En cuanto al papel que ha jugado la ordenación del territorio en todo este proceso de transformación, podemos calificarlo como de insuficiente, ya si bien controló el desarrollo urbano disperso y ordenó usos y problemáticas relacionadas con el invernadero, su labor se inició con actuaciones aisladas que no tenían en cuenta el entorno territorial comarcal, y que no estaban integradas en planes supramunicipales o supracomarcales que tuvieran una visión de conjunto de los procesos territoriales que se estaban produciendo. En los últimos años, con un modelo productivo en marcha que generaba enormes beneficios económicos, y con multitud de feroces procesos de devastación de los recursos comarcales activos, las figuras de planificación integral implementadas ya entrado el siglo XXI sólo podían operar, de forma parcial, paliando los efectos perniciosos de años de descontrol, sin que su actuación pueda conseguir, desde nuestro punto de vista, una mínima restitución del daño ocasionado.

Podemos afirmar que, en Almería, el sector agrícola y después el turístico, han venido a sustituir, en lo referido al desarrollo y al crecimiento económico -junto con sus efectos secundarios-, lo que en otros sitios ha conseguido solamente el desarrollo industrial. En este sentido, y como veremos a continuación, la dependencia de estos dos sectores y los esfuerzos que se hacen desde todos los ámbitos, públicos y privados, por conservar la posición de dominancia adquirida en las últimas décadas, es enorme.

\section{EL SISTEMA URBANO DEL PONIENTE ALMERIENSE COMO ELEMENTO RECTOR DEL DESARROLLO TERRITORIAL}

\subsection{Análisis socioeconómico}

El litoral almeriense, históricamente y hasta los años 60 del pasado siglo, se ha caracterizado por ser un lugar inhóspito, falto de agua y recursos aprovechables, que se mantuvo prácticamente despoblado y sólo ocupado en espacios retranqueados del litoral (Berja, Enix, Níjar, Vera, Cuevas del Almanzora), o plazas fácilmente defendibles y estratégicas (Adra, Mojácar), en donde ahora el éxito agrícola y turístico ha completado un sistema de asentamientos jerarquizado y una nueva red urbana. En el caso concreto del poniente provincial, y partiendo de la base de un sistema urbano desequilibrado -con Berja y Adra como únicas referencias de cierta entidad- caracterizado por los grandes vacíos demográficos, la dinámica económica y social ha terminado por consolidar un sistema urbano y territorial estable y, hasta cierto punto, equilibrado, que se viene manteniendo en sus formas principales, reforzadas constantemente por un continuo crecimiento demográfico (Cuadro 2), desde mediados de los años 90 del pasado siglo hasta nuestros días. 
Cuadro 2. Evolución de la población comarcal y comparativa provincial, 1981-2011.

\begin{tabular}{|l|c|c|c|c|c|c|}
\hline & 1981 & 1991 & 2001 & 2011 & Variación & $\begin{array}{c}\text { Variación \% } \\
(1981=100)\end{array}$ \\
\hline Adra & 17.415 & 20.104 & 21.983 & 24.512 & 7.097 & +41 \\
\hline Berja & 11.169 & 12.054 & 13.312 & 15.388 & 4.219 & +38 \\
\hline Dalías & 3.513 & 3.511 & 3.625 & 3.991 & 478 & +14 \\
\hline El Ejido & 29.486 & 41.374 & 57.877 & 83.774 & 54.288 & +184 \\
\hline Enix & 268 & 241 & 261 & 453 & 185 & +69 \\
\hline Felix & 4.440 & 616 & 573 & 661 & -3.779 & -85 \\
\hline La Mojonera & - & 5.458 & 7.586 & 8.686 & 3.228 & +73 \\
\hline Roquetas de Mar & 18.891 & 26.842 & 50.096 & 89.851 & 70.960 & +376 \\
\hline Vícar & 7.640 & 11.885 & 16.784 & 23.656 & 16.016 & +210 \\
\hline Total comarcal & 92.822 & 122.085 & 172.097 & 250.972 & 158.150 & +170 \\
\hline Total provincial & 410.848 & 455.496 & 536.731 & 702.819 & 291.971 & +71 \\
\hline Comarca/Provinciá (\%) & $22 \%$ & 268 & $32 \% 1$ & 357 & & +58 \\
\hline
\end{tabular}

Fuente: Censos de Población y Padrón Municipal de Habitantes. Elaboración propia.

En los años 80 del pasado siglo, cuando ya estaban asentadas las bases socioeconómicas del modelo de desarrollo actualmente imperante en el poniente, sólo existían cuatro ciudades medias en este ámbito. Adra y Berja, núcleos tradicionales que aún mantenían un gran peso en la comarca; Roquetas, que ya despuntaba como núcleo beneficiado por el desarrollo del turismo y que también participaba del de los invernaderos; y El Ejido, recién independizado de Dalías por su apabullante importancia demográfica (ya era en 1981 el primer núcleo de la comarca en población) y económica (comenzaba a representar la cabeza económica y empresarial del cultivo en invernadero de Almería). Los pueblos de interior (Dalías, Felíx y Enix), en circunstancias diversas, representaban el ocaso del mundo rural español por no ser ya el secano leñoso, el cultivo de huerta y el parral productos ajustados a las necesidades del mercado en esos años.

En 1991 es el momento en que el modelo comienza a estabilizarse en sus bases actuales. Berja, en el interior, se descuelga de los grandes incrementos demográficos; Adra aumenta notablemente, pero los principales incrementos vuelven a concentrarse en El Ejido y Roquetas, que ya despuntan como las cabezas de un sistema urbano muy dinámico y plenamente consolidado en sus características actuales. Por último Vícar, núcleo intermedio entre los dos grandes y situado en las inmediaciones de la carretera nacional 340, irrumpe en estos años como incipiente ciudad media con grandes perspectivas de futuro.

La tendencia se mantiene y se consolida en 2001 y 2011, con incrementos globales especialmente notables en este último periodo intercensal. Los pueblos de interior siguen perdiendo importancia relativa y con pérdidas de población ligeras. Berja se recupera, tímidamente, de su estancamiento. Adra sigue creciendo moderadamente y Vícar, y sobre todo El Ejido y Roquetas, conocen espectaculares incrementos (más de 39.000 nuevos habitantes en el caso de Roquetas en sólo diez años), alcanzando el conjunto comarcal una densidad de población de 258 '5 hab $/ \mathrm{km}^{2}$. Esta evolución marca directamente un espectacular aumento del peso del poniente en la provincia, pasando de suponer poco más de un quinto del total de la población provincial en 1981, a constituir actualmente más de un tercio del total, unos 250.000 habitantes. Y la tendencia indica que este crecimiento continuará en los próximos años.

Por otro lado, en el aspecto socioeconómico, la comarca del poniente destaca, entre todas las comarcas litorales andaluzas, por el enorme peso que aún mantiene en su población ocupada el sector primario (Rodríguez, 2008: 221), si bien según los casos la evolución seguida por los distintos municipios tiene peculiaridades que es necesario comentar. En este caso, y para acotar el análisis, hemos decidido centrarnos 
en la información referida a los elementos rectores de su sistema urbano, las ciudades medias comarcales, que concentran la inmensa mayoría de la actividad, la población y las empresas en este entorno.

Cuadro 3. Población ocupada por sectores económicos en las ciudades medias del poniente almeriense (\%), 1981-2001.

\begin{tabular}{|l|c|c|c|c|c|c|c|c|c|}
\hline & \multicolumn{3}{|c|}{1981} & \multicolumn{3}{c|}{1991} & \multicolumn{3}{c|}{2001} \\
\hline & $1^{\circ}$ & $2^{\circ}$ & $3^{\circ}$ & $1^{\circ}$ & $2^{\circ}$ & $3^{\circ}$ & $1^{\circ}$ & $2^{\circ}$ & $3^{\circ}$ \\
\hline Adra & $57^{\prime} 9$ & $14^{\prime} 8$ & 27,4 & 49,46 & 15,68 & 34,46 & 42,05 & & 39,58 \\
\hline Berja & $50^{\prime} 7$ & $20^{\prime} 7$ & 28,6 & 39,31 & 24,23 & 36,46 & 36,43 & & 43,64 \\
\hline Dalías & $67^{\prime} 0$ & $9^{\prime} 3$ & 23,7 & & & & & & \\
\hline El Ejido & & & & 49,75 & 12,07 & 38,19 & 52,79 & 9,54 & 37,67 \\
\hline Roquetas de Mar & $50^{\prime} 7$ & $15^{\prime} 2$ & 34,2 & 36,4 & 17,09 & 46,51 & 35,59 & & 49,96 \\
\hline Vícar & & & & 65,3 & 15,09 & 19,61 & 52,05 & & 35,46 \\
\hline $\begin{array}{l}\text { Media CM } \\
\text { Comarcales (\%) }\end{array}$ & $56^{\prime} 6$ & 15 & 28,5 & 48,1 & 16,8 & 35,1 & 43,8 & 15 & 41,3 \\
\hline
\end{tabular}

Fuente: Rodríguez Martínez (2008). Elaboración propia.

El 1981, la media de ocupación en el sector primario en las ciudades medias del poniente almeriense era de más del $56 \%$, con el caso sobresaliente de Dalías-El Ejido que en ese año tenía un $67 \%$ de su población activa ocupada en este sector. El sector secundario era especialmente importante en Berja (casi un $21 \%$ ), y con respecto al terciario, ya era notoria su fuerza en Roquetas de Mar (con un 34\%).

En el siguiente registro censal, el sector primario sigue manteniendo un posición de dominancia en la comarca, si bien no es ya el mayoritario en todas las ciudades. En Berja está prácticamente igualado al sector servicios, y en Roquetas es superado por éste último. En todos los demás casos, su peso relativo es menor por el empuje de la construcción y la industria en los municipios costeros, y por la irrupción del turismo de forma definitiva en la comarca.

Finalmente, en 2001, el sector primario no es ya el más importante en Berja y Roquetas, donde el peso del sector servicios se dispara hasta rondar el $50 \%$ de la población ocupada, y se comienza a igualar en el caso de Adra, que encuentra en el turismo y los servicios una alternativa al monopolio agrícola. Éste último, sigue teniendo un importancia apabullante en El Ejido y también en Vícar, donde el invernadero sigue siendo la base, sin alternativas, de la economía local. Finalmente la construcción y la industria, agrupados en el sector secundario, debido al enorme peso de los otros dos sectores, conoce, pese a su crecimiento real en esos años, una estabilización o ligero retroceso comparativo en el conjunto de la comarca.

\subsection{Transformaciones en el sistema urbano y de articulación territorial}

Antes de 1981, los municipios principales del poniente, a excepción de Berja en el interior, ya contaban con algunos de los mayores incrementos de población intercensal de la región, si bien no tan altos como los municipios turísticos malagueños o los incipientemente metropolitanos (Bosque et al., 1979: 100). Esto nos indica que, si bien en este trabajo analizamos el periodo de culminación de un proceso territorial sobresaliente en sus formas y resultados, no es menos cierto que su génesis y pautas de desarrollo tuvieron lugar en décadas anteriores.

Atendiendo a los criterios de centralidad, función, cuota de mercado y movilidad diaria, se diferenciaban ya a finales de los 80 cuatro áreas de atracción en el litoral sur de Almería: la ciudad de Almería, Roquetas de Mar, El Ejido y Adra (Márquez, 1988). Este dato denota, por un lado, la existencia de un red urbana polinuclear en la zona ya desde las primeras etapas de afianzamiento del sistema urbano comarcal, y por otro, la pérdida de importancia de Berja, antiguo centro económico, demográfico, judicial 
y administrativo de la zona suroccidental de la provincia, frente a los pujantes núcleos de población de la costa. En esta primera etapa, era fácil separar las áreas de influencia de la capital y la de los municipios del antiguo campo de Dalías a través del municipio de Enix, dejando a Adra como referencia en el extremo occidental del espacio (Jordá et al., 1989: 182). A partir de este momento, la dinámica comarcal marchó por derroteros dispares. Por un lado, Adra y Berja, pese a sensibles incrementos de la población -sobre todo en el caso abderitano-, no volvieron a hacer sombra a El Ejido o Roquetas en cuanto a importancia urbana y significación funcional. En estos años de fuerte y constante expansión económica, los dos núcleos tradicionales vieron como los nuevos servicios, las grandes áreas comerciales y de ocio (centros comerciales, grandes multinacionales de la alimentación), el poder administrativo (juzgados, instituciones comarcales), y la sede de organismos públicos (Hacienda, Seguridad Social) y de las más importantes empresas comarcales (las grandes cooperativas y multinacionales agrícolas) comenzaban, de forma sistemática, a asentarse en los pujantes núcleos ejidense y roquetero.

Como vemos, esta etapa iniciada a finales de los 70 y culminada a mediados de los 90 es, entre otras cosas, la etapa del definitivo cambio estructural de la comarca. Por un lado, se pasó de un interior históricamente consolidado y densamente poblado a uno decadente y desestructurado, con la salvedad del núcleo de Berja, que no salió hasta fechas recientes de un triste estancamiento. Por otro lado, el litoral, de espacio marginal y despoblado, pasa a ser el núcleo central y fuente de dinamismo y oportunidades. Esto se verificó en una descomposición general de los modos de vida tradicionales sobre los que se había sustentado la importancia funcional del interior comarcal (proceso similar al vivido en otras comarcas agrarias e interiores andaluzas), lo que a su vez coincidió con el auge del turismo de sol y playa y los cultivos forzados, dándole una especial virulencia a este proceso en la comarca. En resumidas cuentas, esto supuso el cambio de la cabecera de Berja a Adra y El Ejido y la aparición de multiplicidad de nuevos grandes núcleos situados en la llanura litoral como síntoma del cambio productivo y territorial habido (Compán, 1985: 190-193). De esta forma, el campo se convirtió en el centro de atracción para un hinterland, rural y decadente, en el que no tenía cabida un desarrollo agrícola y turístico intensivo similar. Con el paso de los años, el aumento demográfico, la especialización productiva y el éxito comercial, el poniente almeriense acabó por convertirse en un auténtico foco de desarrollo regional en el litoral mediterráneo andaluz.

Por otro lado, ya se han tratado los históricos problemas que arrastraba la comarca de falta de jerarquización efectiva de su red urbana, sobre todo en relación con el despoblamiento histórico y el rápido crecimiento de los 70 y 80 del pasado siglo, lo que dio lugar, según algunos autores, a una ausencia efectiva de centralidad (Feria, 1993: 146). A partir de los 90, el éxito urbano de los núcleos de El Ejido y Roquetas de Mar ha conducido a una organización del espacio focalizada en estos dos núcleos, que tiene como segundo escalón en la jerarquía comarcal a los núcleos de Adra (al oeste), La Mojonera y Vícar (en el centro del campo y entre los dos principales) y finalmente Berja, que queda en el interior participando de forma limitada del fenómeno del invernadero y del creciente turismo. Resultado del cambio en la localización del centro de gravedad en la comarca también es el cambio en la denominación comarcal, que ha pasado del tradicional "campo de Dalías", denominación histórica para un territorio rural y despoblado, a "poniente almeriense", nombre más dinámico, que engloba a una realidad territorial mayor reflejo de los nuevos tiempos.

Los cambios económicos y demográficos, también tuvieron consecuencias administrativas. No sólo por la aparición de nuevos núcleos mucho más poblados e importantes que los centros funcionales tradicionales, hecho ya comentado, sino porque la dinámica urbana condujo a una reordenación del poder administrativo en la comarca. El más conocido es el hecho de que el principal núcleo del campo de Dalías, El Ejido, sea el resultado de una escisión del término municipal de Dalías, del que primero llegó a ser capital municipal (1981) y del que, más tarde, se escindió (1982), debido a su pujanza económica y demográfica frente al centro tradicional que quedaba estancado en su ubicación interior y montañosa. Lo mismo ocurrió con Felíx y La Mojonera, escindida del primero en 1989 por idénticas circunstancias. Un proceso similar ha sido el vivido por Vícar, que, para evitar la escisión de su núcleo situado en pleno campo -La Puebla-, trasladó allí la actividad administrativa del ayuntamiento (aunque 
los plenos se siguen celebrando en el pueblo viejo). Finalmente Balanegra, localidad costera incluida en el término de Berja, debido a su posición excéntrica y alejada del núcleo principal municipal y su significativo crecimiento económico reciente, consiguió, en primer lugar, ser reconocida en 1987 como Entidad de Ámbito Territorial Inferior al Municipios (EATIM), para más tarde promover un referéndum de independencia entre sus vecinos en marzo de 2004 -con resultado afirmativo-, $y$, tras múltiples avatares judiciales y administrativos, conseguir en 2011 la categoría de Entidad Local Autónoma (ELA), desde la que las autoridades locales siguen trabajando por la segregación. En definitiva, un largo proceso de reestructuración común a toda la comarca, en el que el poder político y administrativo tiende a adaptarse y pretende ser reflejo de la nueva dinámica urbana en la comarca.

Como muestra palpable de todo lo anterior, ya el Plan de Ordenación Subregional del poniente almeriense reconocía explícitamente todas estas dinámicas y áreas de influencia en un mapa de síntesis que recogía y sintetizaba el nuevo escenario urbano que marca la dinámica territorial de esta parte de la provincia de Almería.

Figura 1. Estructura funcional del poniente almeriense propuesta por el POTPA.

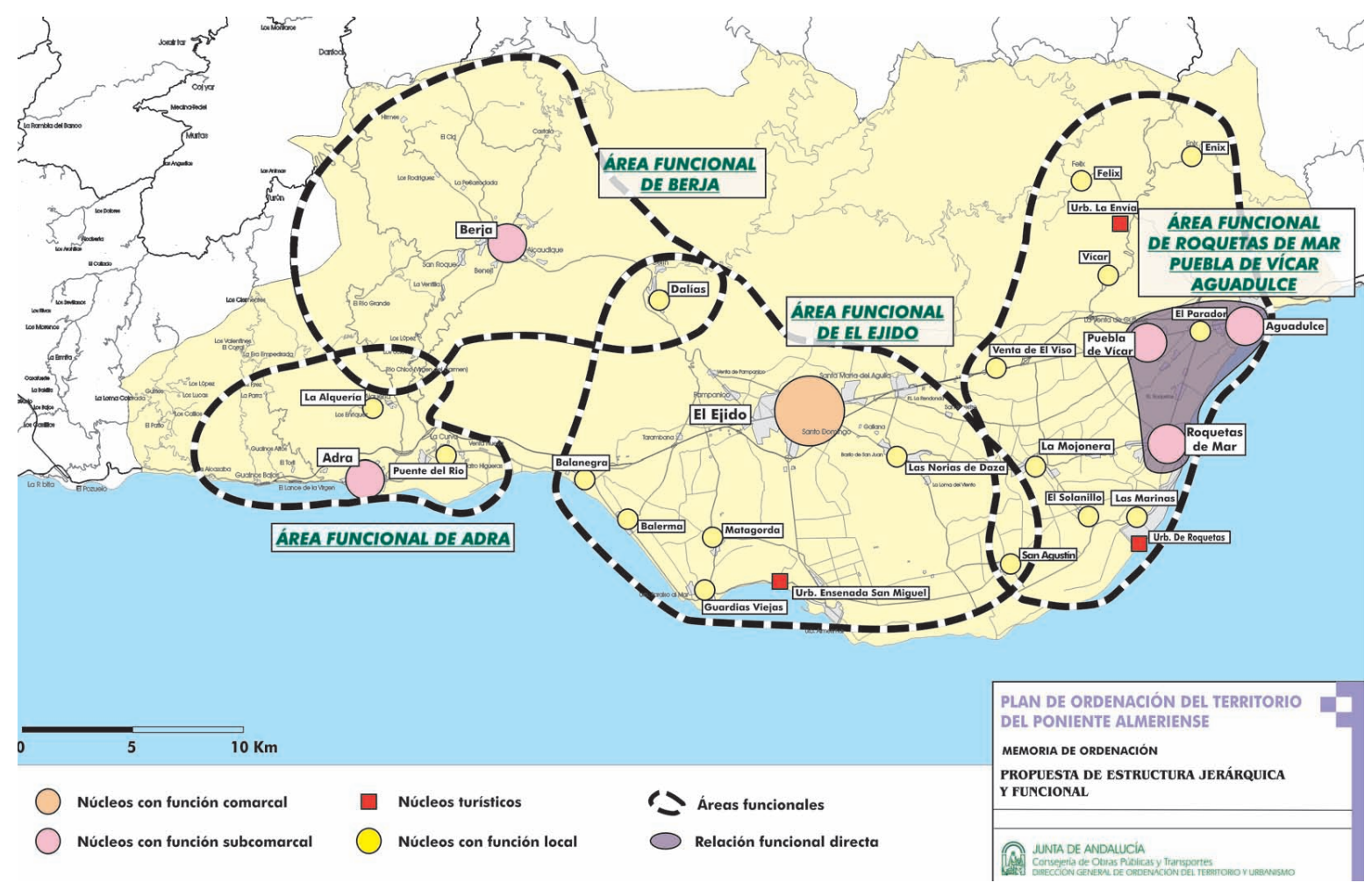

Fuente: Plan de Ordenación del Territorio del Poniente Almeriense, 2002.

Como vemos en la Figura 2, Adra queda restringida a un área de influencia coincidente con su municipio (no se refleja aquí el indudable peso que tiene en la costa oriental granadina), Berja en similar situación (en este caso con influencia hacia el norte sobre la Alpujarra almeriense y granadina), y por otro lado los dos grandes focos urbanos del campo de Dalías: por un lado El Ejido, que se erige en el núcleo central de la comarca del poniente, y el triángulo Vícar-Roquetas-Aguadulce, que articula en torno a sí la zona más oriental de la comarca y que tiene indudables relaciones comerciales, de movilidad, administrativas y funcionales con el área urbana de Almería, de la que es vecina por el Este.

Finalmente, hemos de destacar que la red urbana del poniente almeriense ha terminado por conformar un auténtico sistema territorial basado en la existencia de seis ciudades medias, dispuestas de forma uniforme por el espacio comarcal, que aparecen definitivamente jerarquizadas una vez consolidadas las dinámicas territoriales iniciadas en los años 50 del pasado siglo y aceleradas desde los años 90 del mismo. 
Este caso constituye, a nuestro modo de ver, uno de los ejemplos más acabados de cuantos existen en la Andalucía litoral de red urbana con funciones articuladoras y equilibrantes del desarrollo de un territorio extraordinariamente dinámico e históricamente muy caótico en lo referido a su sistema de ordenación y usos, y que hoy aparece como un espacio plenamente organizado en torno a su red de ciudades. Así mismo, entendemos que a través de la constitución de redes de cooperación interurbana en una estructura funcional polinuclear como la que existe en este caso, tal y como se reconoce y por lo que se apuesta decididamente en la planificación regional vigente, se potencia y garantiza una efectiva intermediación urbana entre los grandes centros nacionales y regionales y el tejido productivo e innovador sobre el que se sustenta el poniente almeriense, ventaja nada despreciable sobre otros espacios andaluces peor conectados y articulados.

Figura 2. Concepción relacional del actual sistema territorial del poniente almeriense, construido sobre su red de ciudades medias.

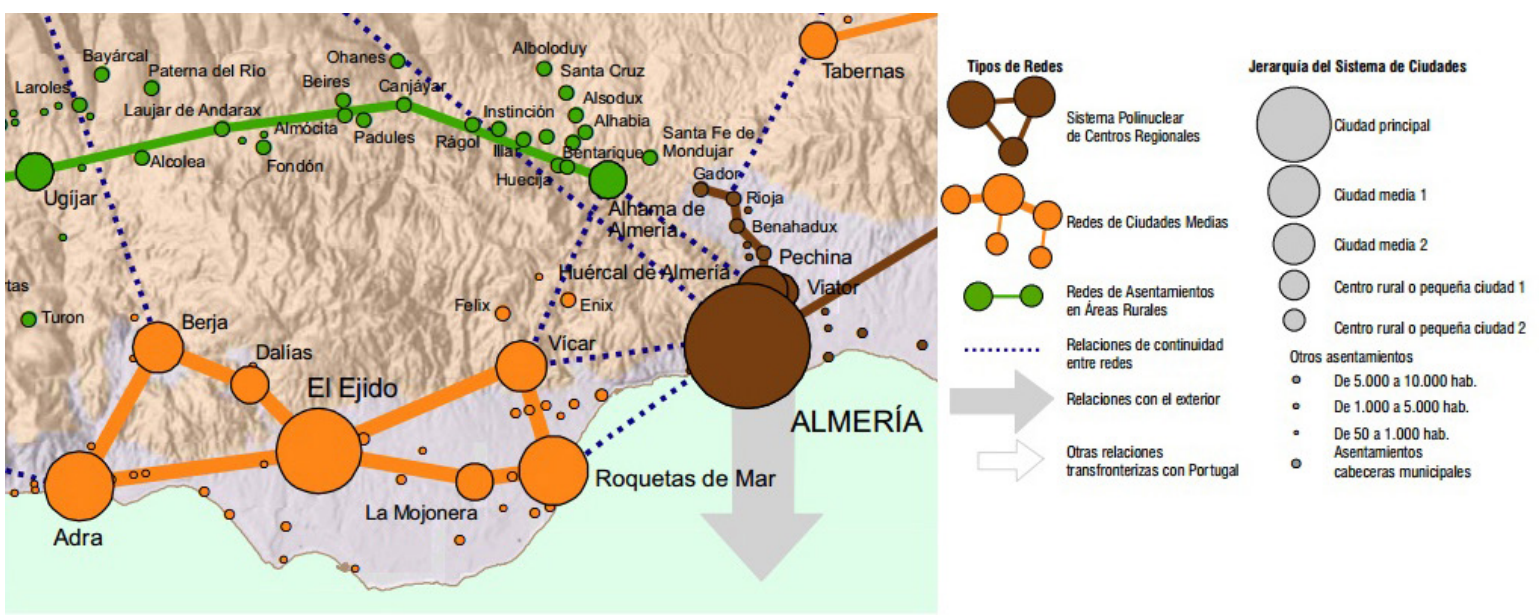

Fuente: Plan de Ordenación del Territorio de Andalucía, 2006.

\section{EL MODELO DE INNOVACIÓN TERRITORIAL EN EL PONIENTE ALMERIENSE}

Los defensores de los sistemas nacionales o regionales de innovación adjudican una gran importancia a la proximidad espacial, las externalidades, la cultura e identidad regional y el proceso de aprendizaje colectivo en la creación y difusión de las innovaciones (Koschatzky, 2000). Se entiende por sistemas de innovación regional los sistemas compuestos por las organizaciones e instituciones de un territorio que influyen en el desarrollo, difusión y uso de las innovaciones (Edquist, 1997: 14). Una definición teórica de este concepto tiene en cuenta tres aspectos. Primero se trata de un sistema donde actúan e interactúan distintos agentes e instituciones; segundo, las actividades analizadas están ligadas a la innovación; y tercero, se trata de un sistema nacional o regional, lo que implica un enfoque geográfico en sus concepción y análisis (Heijs, 2001).

Adentrándonos de lleno en la vertiente geográfica de esta cuestión, comprobamos como en nuestro mundo existen factores económicos y territoriales que presionan hacia la remetropolización de las actividades económicas y de la innovación (Veltz, 1999), frenando así la tendencia a la descentralización que en esta materia se venía produciendo de forma general hasta hace unas décadas. Poniendo como ejemplo el caso de Andalucía, en ella se da una configuración económico-territorial de metrópolis en red conformada por las grandes aglomeraciones urbanas y los principales centros urbanos regionales, que concentra los procesos económicos y productivos y retroalimenta, por atracción y generación en un contexto favorable, el desarrollo de procesos innovadores (Ruíz, 2004 : 87). De este modo, la presencia de servicios avanzados se convierte en elemento clave de la difusión y generación no sólo de actividades de I+D sino también de innovación. Debido a la ausencia de éstos, el territorio andaluz se caracteriza desde el 
punto de vita de la innovación no sólo por la macrocefalia urbana sino también por la monoespecialización y poca intensidad tecnológica sectorial. En este marco, los sistemas territoriales articulados en torno a ciudades intermedias constituyen el motor de cambio territorial de la innovación en estos espacios, ya que permiten la difusión y la generación de nuevos focos innovadores complementarios a los principales evitando la focalización exclusiva del desarrollo en las grandes urbes. El poniente almeriense, que ya ha construido previamente un modelo económico competitivo estructurado en torno a su red urbana polinuclear de ciudades intermedias, goza de una auténtica "atmósfera industrial", donde se acumula y difunde rápidamente el conocimiento (Tolón et al., 2010: 12), disfrutando de un posición consolidada en el sistema innovador y de desarrollo regional. De hecho, este territorio se caracteriza actualmente por albergar madias-altas y altas tecnologías, estatus que en Andalucía sólo alcanzan a igualar las aglomeraciones urbanas de las principales ciudades de la región (Ruíz, 2004: 83).

Por otro lado, la capacidad de los ámbitos territoriales para llevar a cabo actividades de I+D empresarial y en definitiva, de innovación, no sólo está en estrecha relación con la existencia de una estructura innovadora básica como la descrita, sino también, aunque en menor medida, con un determinado grado de diversificación productiva y tecnológica. Esto es algo verdaderamente extraño en Andalucía, si bien en este aspecto la comarca del poniente constituye una excepción, ya que en ella predominan las empresas dominadas por los proveedores y de producción a gran escala (Ruíz, 2004: 83). Finalmente, por la alta especialización en un mismo sector tecnológico de las empresas innovadoras del poniente, independientemente de que su modelo productivo y el impacto de sus adelantos haya desbordado los límites físicos de la comarca, se puede considerar que el poniente constituye un auténtico "sistema de innovación" (Carlson, 1995; Bresci, 1997).

Todo esto nos permite contextualizar la evolución del sector empresarial e industrial desarrollado en estas últimas décadas en el poniente almeriense asociado al campo invernado (Cuadro 4). A finales de los 80 ya empiezan a aparecer los primeros suministradores de insumos con sede en la zona. En esos años los agricultores empiezan a organizarse en cooperativas de productores, desprendiéndose así de una histórica dependencia del campo almeriense de los productores y empresarios agrícolas murcianos y valencianos (esto ocurría con la comercialización de la uva de embarque, las naranjas del Andarax o los productos de huerta del Almanzora). La dimensión que en esos años alcanzaba ya la producción, y una tendencia siempre positiva de ésta y sus rendimientos lo favorecía. Así como la extendida evidencia por parte de la población de los abusos en las condiciones impuestas por estos empresarios foráneos.

Desde los primeros 90 este escenario se consolidó, resultando una disminución del nivel de dependencia del suministro externo de imputs y generalizándose la creación de empresas autóctonas relacionadas con todos las etapas del proceso productivo, desde el diseño de nuevas explotaciones, hasta la investigación química y biológica, pasando por los sistemas de riego o los contactos internacionales para la comercialización del género. El nacimiento de la Universidad de Almería en 1993 como centro especializado de investigación agrario contribuyó sobremanera a este hecho.

El crecimiento y diversificación de las actividades industriales y de servicios surgidas en torno a la agricultura intensiva -plásticos y cartones, almacenaje y logística, maquinaria de manipulación, transportehan dado lugar en la actualidad a una compleja red de relaciones económicas y empresariales que definen la existencia de un auténtico clúster empresarial almeriense (Pérez, 2009: 163; Aznar et al., 2010: 178), con su centro de gravedad en el poniente y ramificaciones en el campo de Nijar, el bajo Almanzora y la costa oriental granadina, que ha conseguido generar un auténtico mercado regional de servicios y suministros alentado por un demanda siempre creciente y un sobresaliente know-how que exporta métodos y sistemas a otras zonas productoras del mediterráneo y el mundo (Italia, Croacia, Israel, Chile o China). 
Cuadro 4. Innovaciones técnicas y de gestión en el campo bajo plástico almeriense.

\begin{tabular}{|l|l|}
\hline \multicolumn{1}{|c|}{ ADELANTO TÉCNICO O CIENTÍFICO } & AÑO \\
\hline Enarenado & 1956 \\
\hline Invernadero parral de plástico & 1968 \\
\hline Semillas híbridas & 1975 \\
\hline Riego por goteo & 1977 \\
\hline Plástico térmico & 1982 \\
\hline Tubería con gotero integrado & 1986 \\
\hline Cultivos sin suelo & 1990 \\
\hline Abejorros & 1991 \\
\hline Tomate larga vida & 1992 \\
\hline Carrito recolección & 1996 \\
\hline Invernadero industrial & 1997 \\
\hline Cabezal automatizado & 1999 \\
\hline \multicolumn{1}{|c|}{ TOMA DE CONCIENCIA GENERAL SOBRE LA NECESARIA } \\
\hline SOSTENIBILIDAD DEL SISTEMA & \\
\hline Automatización del sistema de riego y control climático & 2000 \\
\hline Fumigador automático & 2001 \\
\hline Lucha integrada & 2003 \\
\hline Constatación científica de la influencia sobre el cambio climático & 2008 \\
\hline Arquitectura bioclimática aplicada al diseño del invernadero & 2009 \\
\hline Planes públicos de renovación de invernaderos antiguos & 2010 \\
\hline Gestión energética integral & 2012 \\
\hline Nuevas estructuras, nuevos materiales & \\
\hline
\end{tabular}

Fuente: Aznar Sánchez y Sánchez Picón (2010: 174). Elaboración propia.

Frente a este panorama, no optimista pero sí globalmente positivo, ya comienza a haber estudios que, a partir de un mejor conocimiento de la realidad empresarial almeriense, y sin negar la existencia de este cluster empresarial agroindustrial con sede en la provincia, vienen a confirmar que existe en este tipo de modelos productivos una excesiva, cuando no total, dependencia de multinacionales, y un uso de tecnologías no del todo adaptadas al área productiva local (Pérez, 2009). Esto nos conduce ante un panorama en que la mejora tecnológica viene dada por las presiones de la demanda más que por iniciativas propias locales, y el camino para esa mejora depende en muchos casos (semillas, químicos) de multinacionales con sede fuera de Andalucía. Por ello, el modelo innovador almeriense presenta rémoras y dependencias exteriores que condicionan su capacidad de mejora futura y lo vuelven más dependiente de decisiones corporativas ajenas a la dinámica socioeconómica local.

Además, en el contexto actual no podemos dejar de lado el hecho de que comarcas andaluzas muy dinámicas, con un tejido innovador consolidado como ocurre en el caso del poniente de Almería, pueden perder potencial y ver comprometido su futuro si la decadencia de la economía regional y la falta de competitividad que caracterizan hoy día a el sistema productivo andaluz se mantienen en los próximos años. El litoral mediterráneo regional y, como parte fundamental del mismo, el poniente almeriense, constituyendo un mismo sistema territorial y urbano cada día más eficaz y mejor articulado, no podrán competir con las grandes urbes nacionales ni regionales y otros espacios innovadores de su entorno -pienso, dentro del ámbito hortofrutícola, en las vegas murcianas o el Vinalopó alicantino -, si quedan atrapadas en una economía dependiente, burocratizada y sin fuerza competitiva. 


\section{CONCLUSIONES}

El poniente de Almería constituye, aún hoy, una tierra llena de desafíos y problemáticas extraordinariamente llamativas para el análisis geográfico. Un lugar marcado por procesos, relativamente recientes en el tiempo, que protagonizan un territorio "nuevo", no sólo en lo que respecta a su sistema territorial y de articulación espacial (nuevos lugares y referencias inexistentes hace apenas 40 años definen hoy la pauta territorial y focalizan el día a día de sus habitantes), sino que hablamos de un espacio que, a partir de la supervivencia económica de su modelo de desarrollo, ha logrado convertirse en una sociedad con un marcado carácter innovador, algo ignoto en otros espacios andaluces dependientes del sector primario.

Es evidente, así mismo, que el poniente almeriense ha protagonizado un dinamismo socioeconómico que ha superado a la ordenación del territorio y a la planificación en todas sus etapas, desde los primeros y esquemáticos esbozos del INC hasta las logradas imágenes de conjunto ofrecidas por el plan subregional de 2002 y el regional de 2006. En relación con esta idea, entendemos que se hace inmediata la necesidad de implementar en territorios de este tipo, muy dinámicos, densamente poblados y en constante evolución, modelos de planificación estratégica hasta ahora exclusivos de grandes ciudades, que permitan dejar atrás el modo tradicional de planificar y ordenar el territorio y sus problemáticas para pasar a un nuevo modelo verdaderamente participativo y social que permita, en este caso, a los habitantes del poniente almeriense orientar y dirigir el modelo de desarrollo y crecimiento existente en su comarca de una forma acorde con sus expectativas y los retos que se le vienen planteando.

En la actualidad, la dinámica territorial que sigue el poniente desde el último tercio del siglo XX, ha borrado del mapa viejas relaciones funcionales entre núcleos, ha creado nuevos centros de poder e influencia en el territorio, y ha logrado configurar un espacio mejor y más articulado, entre otras cosas, debido al crecimiento imparable de sus dos principales núcleos de población -El Ejido y Roquetas de Mar-, la consolidación de los viejos centros preexistentes, y al éxito de las actuaciones del INC, que, junto con iniciativas agronómicas e hidrológicas, también diseñó y puso en marcha asentamientos para colonos que, con el paso de los años, han ido ganando importancia en el sistema urbano comarcal y provincial y sirven actualmente como punto de equilibrio y eslabón entre los grandes núcleos de población, los centros tradicionales, y el hábitat disperso y rural que se desarrolla entre el mar de plásticos y anexo a las principales vías de comunicación.

Junto con los cambios que en este trabajo hemos analizado, centrados en la generación de procesos de desarrollo y la consecución de un crecimiento económico sostenido en el tiempo, también aparecieron nuevos retos ambientales y territoriales, y de la no superación de muchos de ellos, llegaron las grandes problemáticas que afectan a la comarca del poniente de Almería en la actualidad. La necesidad de mejora técnica constante, el imprescindible aumento de los rendimientos en el campo para ser competitivos a escala global, la gestión eficiente de recursos cada día más escasos... supone un desafío diario para un territorio y una sociedad que creía haber alcanzado la estabilidad y la prosperidad como un logro definitivo en los años 90 del pasado siglo.

Entre los grandes retos que tiene en su haber el poniente de Almería para los próximos años se encuentran dos que consideramos capitales. Por un lado la necesaria solución a la feroz competencia entre los invernaderos y el urbanismo residencial por el agua, el suelo y la conservación del paisaje, especialmente sensible este punto en relación con los espacios naturales de alto valor ecológico que se encuentran en la comarca (Albuferas de Adra, Punta Entinas-Sabinar, Sierra de Gádor). Si bien el Plan Subregional supuso un hito en la racionalización de los desarrollos incontrolados habituales en periodos anteriores en ambas materias, no es menos cierto que la ausencia de alternativas agrícolas al aumento del terreno invernado y la pasada burbuja inmobiliaria han hecho que hoy día el número de invernaderos ilegales y de urbanizaciones en espacios antes no urbanizables no haya dejado de crecer pese a las nuevas restricciones técnicas y legales. El segundo gran problema al que tiene que hacer frente la comarca, y nos situamos de lleno en del mundo agrario, guarda relación con las deficiencias estructurales que año a año se detectan en materia de gestión de los flujos comerciales en los que debe encontrar acomodo la producción 
hortofrutícola. Los acuerdos UE-Marruecos que dañan la posición de Almería y sus productos en el mercado europeo, la necesidad de una concentración de la producción, favoreciendo el cooperativismo y el asociacionismo entre los pequeños agricultores, las cada vez más habituales campañas de desprestigio exterior (como la habida en 2011 en toda Europa, con especial fuerza en Alemania, por la bacteria E-Coli proveniente de Egipto), la ausencia de marcas de calidad que permitan reconocer los productos del campo de Almería en el mercado, y la aparición de nuevas plagas y virus debido a la debilidad biológica de las variedades cultivadas (que además hacen necesaria la incorporación de una mayor cantidad de imputs por parte de los agricultores), han hecho que cada año los beneficios de los agricultores sean más pequeños e inseguros, y el nivel de endeudamiento de muchos de ellos sea asfixiante. Creemos que la salida a este escenario pasa por un mayor impulso a la investigación, una apuesta por la calidad certificada de los productos del campo, más colaboración entre administraciones y más respaldo público a un sector eminentemente productivo y competitivo, que genera decenas de miles de empleos técnicos y especializados, y que quizá, por su especial desenvolvimiento comercial, ha conseguido lo más difícil en estos casos: crear una sociedad marcada por la necesidad constante de la innovación.

A estos dos problemas principales que comentamos se añaden los impactos y problemáticas incipientes generadas sobre los recursos básicos que sustentan el sistema productivo comarcal -intrusión salina en los acuíferos debido a la sobreexplotación de los mismos, la contaminación del suelo y subsuelo por productos químicos y los residuos agrícolas y urbanos-, y junto con estos la sobrecarga de las infraestructuras viarias comarcales o el aumento imparable de las necesidades de inversión por campaña agrícola (para imputs químicos, introducción de nuevas variedades de semillas, acceso a las mejoras técnicas y estructurales que se vienen produciendo en invernaderos, etc.).

No podíamos dejar a un lado la referencia al enorme reto ambiental y por la sostenibilidad que tiene esta comarca y su modelo productivo. No hay que obviar que la dinámica económica del poniente almeriense es, casi literalmente, una constante huida hacia adelante, una lucha diaria por seguir siendo competitivos en un mercado global con productores perfectamente organizados. Los problemas que hemos citado ponen en jaque, a medio plazo, las bases productivas de una comarca, que, hasta ahora, no ha asumido, a través de una apuesta por la sostenibilidad, la fragilidad ambiental sobre la que se sostiene su supervivencia.

\section{BIBLIOGRAFÍA}

AA.VV. (1981, 1991, 2001): Censo de población y vivienda. Instituto Nacional de Estadística. Madrid.

AA.VV. (2hMA). Instituto de Estadística y Cartografía de Andalucía. Sevilla.

AA.VV. (2002): Plan de Ordenación del Territorio del poniente de la provincia de Almería. Consejería de Obras Públicas y Transportes. Junta de Andalucía. Sevilla. 2 Vols. 212 pp.

AA.VV. (2006): Plan de Ordenación del Territorio de Andalucía. Consejería de Obras Públicas y Transportes. Junta de Andalucía. Sevilla. 206 págs.

AA.VV. (2012): Sistema de Información Multiterritorial de Andalucía (SIMA). Sevilla. Consejería de Economía, Innovación, Ciencia y Empleo.

AZNAR SÁNCHEZ, J.A., SÁNCHEZ PICÓN, A. (2010): "Innovación y distrito en torno a un "milagro": la configuración del sistema productivo local de la agricultura intensiva de Almería". Revista de Historia Industrial, año XIX, $\mathrm{N}^{\circ} 1$, pp. 157-193.

BOSQUE MAUREL, J., VILLEGAS MOLINA, F. (1979): "Cambios estructurales en la red urbana de Andalucía Oriental”. Revista de Estudios Regionales, nº4, pp. 89-121.

BRESCI Y MALERBA, F. (1997): "Sectorial Innovation Systems: Technological Regimes, Schumpeterian Dynamics and Spatial Boundaries". En Edquist, C. (ed). Systems of Innovation. Technologies, Institutions and Organizations (pp. 130-155). London and Washington, Pinter. 
CARAVACA BARroso, I., GONZÁlez ROMERO, G., MENDOZA BONET, A., SilVA PÉREZ, R. (2009): Dinamismo, innovación y desarrollo en ciudades pequeñas y medias de Andalucía. Sevilla, Consejo económico y Social, Junta de Andalucía. 392 pp.

CARLSON, B. (ed.) (1995): Technological systems and economic perfomance: the case of factory automation. Kluver. Dordrecht.

COMPÁN VÁZQUEZ, D. (1985): "Dinámica locacional reciente de la población en el espacio almeriense: reestructuración de la red urbana tras la quiebra de la agricultura tradicional y la expansión del turismo y los cultivos extratempranos". Paralelo 37, No8-9, Volumen Homenaje a Manuel de Terán, pp. 183-200.

DE LA HERA DÍAZ DE LIAÑO, G. (1998): "Transformaciones del litoral desde mediados del siglo XX". Boletín de la $A G E, n^{\circ} 25$, pp. 109-120.

EDQUIST, J. (1997): Systems of Innovation. Technologies, Institutions and Organizations. London and Washington. Pinter. Publishers.

HEIJS, J. (2001): Sistemas nacionales y regionales de innovación política tecnológica: una aproximación teórica. Documento de trabajo $\mathrm{n}^{\circ} 24$. Instituto de Análisis Industrial y Financiero de la Universidad Complutense de Madrid (IAIF).

FERIA TORIBIO, J.M. (1993): El sistema urbano andaluz. Aglomeraciones urbanas, áreas de centralidad y ámbitos desarticulados. Instituto de Desarrollo Regional. Consejería de Obras Públicas y Trasportes. Sevilla. 310 págs.

GARCÍA MANRIQUE, E., OCAÑA OCAÑA, C. (1982): "La organización espacial de la costa mediterránea andaluza". Baetica, No5, pp. 15-57.

HERNÁNDEZ PORCEL, M. C. (1986): "La agricultura intensiva en el campo de Dalías". Paralelo 37, $\mathrm{N}^{\circ} 10$, pp. 133-140.

HERNÁNDEZ PORCEL, M. C. (1994): "Agricultura y turismo en el campo de Dalías: posibles conflictos". En Desarrollo regional y crisis del turismo en Andalucía: actas del simposio hispano-francés. Almería 2529 de junio de 1991, pp. 147-170.

JIMÉNEZ DÍAZ, J.F. (2008): "Estudio de caso del Poniente Almeriense. Glocalización de la agricultura". Papers, No90, pp. 83-104.

JIMÉNEZ DIAZ, J.F. (2011): "Procesos de desarrollo en el poniente almeriense: agricultores e inmigrados". Revista de Estudios Regionales, No90, pp. 179-205.

JORDÁ BORRELL, R., CANO GARCÍA, G. (1989): "Núcleos y comarcas en la articulación del espacio almeriense". Paralelo 37, Nº13, pp. 177-189.

KOSCHATZKY, K. (2000): "The regionalisation of innovation policy in Germany-theoretical Foundations and recent experience". Arbeitspapiere Unternehmen und Region, $\mathrm{N}^{\circ} 1$.

LARA VALLE, J.J. (1980): "Factores y condicionantes de la expansión turística de la Costa de Almería". Anales del Colegio Universitario de Almería, II, pp. 115-151.

LARRUBIA VARGAS, R. (2010): “Cambios en la comercialización agraria: una visión desde el sector hortofrutícola del sector andaluz". Boletín de la AGE, N52, pp. 117-141.

MÁRQUEZ DOMÍNGUEZ, J.A. (1988): "El comercio en Andalucía”, en Geografía de Andalucía, Tomo VI. Editorial Tartessos. Sevilla.

OCAÑA OCAÑA, C., GÓMEZ MORENO, M.L. (1992): "El litoral andaluz y la red de autopistas europeas: una inserción deficiente". Estudios Regionales, No32, pp. 139-151.

PÉREZ MESA, J.C. (2009): "Multinacionales y difusión de tecnología en clusters agrindustriales: el caso almeriense". Revista de Estudios Regionales, n86, pp. 155-180. 
RIVERA MENÉNDEZ, J. (1996): "Aspectos sociales de la política del Instituto Nacional de Colonización en el campo de Dalías (Almería)". Cuadernos geográficos de la Universidad de Granada, No26, pp. 115-138.

RIVERA MENÉNDEZ, J. (2000): La política de colonización agraria en el Campo de Dalías (1940-1990). Instituto de Estudios Almerienses. Caja Rural de Almería. Almería. 521 pp.

RODRÍGUEZ MARTÍNEZ, F. (1991): "El impacto ambiental del turismo". En Desarrollo regional y crisis del turismo en Andalucía. Actas del simposio hispano-francés. Instituto de Estudios Almerienses. Casa de Velázquez. Almería. 382 pp.

RODRÍGUEZ MÁRTÍNEZ, F. (2008): "Las ciudades medias andaluzas. Cambios básicos durante el último medio siglo", en BOSQUE, J. y MARTÍN, M.A. (coord.) Boletín de la Real Sociedad Geográfica, Homenaje a Joaquín Bosque Maurel, pp.199-238.

RUíZ RODRÍGUEZ, F. (2004): "Análisis comarcal de las actividades empresariales de I+D en Andalucía". Investigaciones Geográficas, No34, pp. 77-99.

TOLÓN BECERRA, A., LATRA BRAVO, X. (2010): "La agricultura intensiva del poniente almeriense. Diagnóstico e instrumentos de gestión ambiental". M+A, Revista Electrónica de Medio Ambiente, $N^{\circ} 8$, pp.18-40.

VELTZ, P. (1999): Mundialización, ciudades y territorios. Ariel. Barcelona. 254 pp. 